See Article page 850 .

\section{Commentary: More R-E-S-P-E-C-T for the mitral subvalvular apparatus}

\author{
Eric J. Charles, MD, PhD, and \\ J. Hunter Mehaffey, MD, MSc
}

Revascularization? Undersizing annuloplasty? Augmentation of the subvalvular apparatus? Valve replacement? A combined approach? Understanding the journey to determine the optimal correction for ischemic mitral regurgitation (MR) is best summarized in the following quote by neuroscientist Vilayanur Ramachandran: "Science is like a love affair with nature; an elusive, tantalizing mistress. It has all the turbulence, twists and turns of romantic love, but that's part of the game." Nappi and colleagues, in the Papillary Muscle Approximation Trial and their subsequent post hoc subanalysis, concluded that patients who underwent complete revascularization combined with mitral valve (MV) papillary muscle approximation, compared with restrictive annuloplasty, had improved left ventricular remodeling and MV geometry and less MR recurrence, regardless of preoperative symmetry of leaflet tethering. ${ }^{2,3}$ In addition, in the moderate ischemic MR trial performed by the Cardiothoracic Surgical Trials Network, the addition of undersizing annuloplasty to coronary revascularization did not yield increased left ventricular reverse remodeling and was associated with increased adverse events. Thus, we continue to question when and how to address the MV in ischemic MR. ${ }^{4}$

In this issue of the Journal, Xu and colleagues ${ }^{5}$ evaluate the effect of undersizing annuloplasty on left ventricular geometry and mechanics in a porcine model of ischemic MR. Compared with papillary muscle approximation, undersizing annuloplasty was associated with lower resultant ejection function, less wall thickening (which was used as a

\footnotetext{
From the Division of Cardiac Surgery, Department of Surgery, University of Virginia, Charlottesville, Va.

Disclosures: The authors reported no conflicts of interest.

The Journal policy requires editors and reviewers to disclose conflicts of interest and to decline handling or reviewing manuscripts for which they may have a conflict of interest. The editors and reviewers of this article have no conflicts of interest.

Received for publication Oct 26, 2020; revisions received Oct 26, 2020; accepted for publication Oct 27, 2020; available ahead of print Nov 5, 2020.

Address for reprints: Eric J. Charles, MD, PhD, Department of Surgery, University of Virginia, PO Box 800679, Charlottesville, VA 22908 (E-mail: ec4wx@virginia. edu).

J Thorac Cardiovasc Surg 2022;164:862-3

$0022-5223 / \$ 36.00$

Copyright $₫ 2020$ Published by Elsevier Inc. on behalf of The American Association for Thoracic Surgery

https://doi.org/10.1016/j.jtcvs.2020.10.105
}

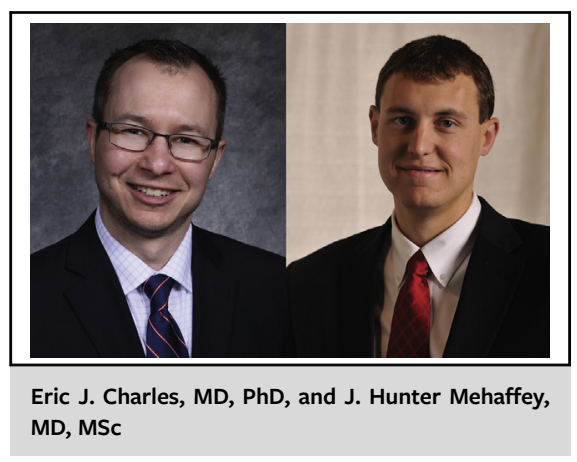

CENTRAL MESSAGE

In a model of ischemic mitral regurgitation, undersizing annuloplasty restored valve competence but not ventricular mechanics, supporting the importance of addressing the subvalvular apparatus.

marker of contractility), lower radial velocities, and a non-physiologic ventricular shape deformity. The authors concluded that undersizing annuloplasty restored valvular competence but at the cost of impaired ventricular mechanics, whereas subannular correction with papillary muscle approximation achieved both improved valve and ventricular function. Thus, the authors propose that valve repair strategies should focus on restoring valve function while preserving or restoring ventricular mechanics.

The authors are to be commended for performing this welldesigned project, which required multiple months of animal care and housing. In this study, the authors induced a myocardial infarction in the animals with coronary injection of ethanol 2 months before operating on them. They were then assigned to either undersizing annuloplasty or nonannular papillary muscle manipulation, followed by an additional 3 months of recovery, before final study evaluation. Data obtained from longitudinal large animal studies can be extremely valuable; however, we must be mindful of the inherent limitations present in a nonrandomized, preclinical study with a small sample size and an approximately $40 \%$ mortality/exclusion rate. While these numbers are often expected when performing such experiments, we are remiss to not contextualize the findings.

Nonetheless, these data further support the importance of addressing the subvalvular apparatus and not focusing solely on the annulus. As we have commented previously, 
MV repair with papillary muscle manipulation to correct leaflet tethering may be the optimal approach to restore valve competence, improve the degree of ventricular reverse remodeling, and reduce the likelihood of MR recurrence. ${ }^{6}$ Thankfully, the credits are not yet ready to roll on the ischemic MR story, which provides us with plenty of time to continue debating how best to manage this heterogeneous spectrum of disease.

\section{References}

1. Nagaswami V. All in the brain. The Hindu. 2011. Available at: https://www. thehindu.com/features/magazine/All-in-the-brain/article15411641.ece. Accessed October 25, 2020.
2. Nappi F, Lusini M, Spadaccio C, Nenna A, Covino E, Acar C, et al. Papillary muscle approximation versus restrictive annuloplasty alone for severe ischemic mitral regurgitation. J Am Coll Cardiol. 2016;67:2334-46.

3. Nappi F, Spadaccio C, Nenna A, Lusini M, Fraldi M, Acar C, et al. Is subvalvular repair worthwhile in severe ischemic mitral regurgitation? Subanalysis of the papillary muscle approximation trial. J Thorac Cardiovasc Surg. 2017;153: 286-95.e2.

4. Smith PK, Puskas JD, Ascheim DD, Voisine P, Gelijns AC, Moskowitz AJ, et al Surgical treatment of moderate ischemic mitral regurgitation. N Engl J Med. 2014; 371:2178-88.

5. Xu D, McBride E, Kalra K, Wong K, Guyton RA, Sarin EL, et al. Undersizing mitral annuloplasty alters left ventricular mechanics in a swine model of ischemic mitral regurgitation. J Thorac Cardiovasc Surg. 2022;164: 850-61.e8.

6. Charles EJ, Kron IL. Repairing the mitral subvalvular apparatus: the new frontier J Thorac Cardiovasc Surg. 2017;153:284-5.

\section{Commentary: Ischemic mitral} regurgitation: From annular restriction to papillary approximation, is it time to reconsider the lost technique?

\author{
Mario Castillo-Sang, MD, ${ }^{\mathrm{a}}$ Tom C. Nguyen, MD, ${ }^{\mathrm{b}}$ and \\ Rochus K. Voeller, MD
}

The undersizing annuloplasty popularized by Bolling and colleagues ${ }^{1}$ for ischemic mitral regurgitation is criticized for being an annular solution to a ventricular problem with significant regurgitation recurrence. ${ }^{2-4}$ This was confirmed in a randomized trial comparing repair and replacement. $^{5}$ A ventricular repair for ischemic mitral regurgitation was first reported by Kron and colleagues ${ }^{6}$ with posterior papillary muscle relocation, but it was Hvass and colleagues ${ }^{7}$ who proposed the papillary muscle sling.

\footnotetext{
From the ${ }^{a}$ Department of Cardiothoracic Surgery, Saint Elizabeth Healthcare, Edgewood, Ky; ${ }^{\mathrm{b}}$ Department of Cardiothoracic and Vascular Surgery, McGovern Medical School, University of Texas Health Science Houston, Houston, Tex; and ${ }^{\mathrm{c}}$ Division of Cardiothoracic Surgery, Department of Surgery, University of Minnesota Medical School, Minneapolis, Minn.

Disclosures: The authors reported no conflicts of interest.

The Journal policy requires editors and reviewers to disclose conflicts of interest and to decline handling or reviewing manuscripts for which they may have a conflict of interest. The editors and reviewers of this article have no conflicts of interest.

Received for publication Oct 13, 2020; revisions received Oct 13, 2020; accepted for publication Oct 15, 2020; available ahead of print Oct 22, 2020.

Address for reprints: Mario Castillo-Sang, MD, Department of Cardiothoracic Surgery, Saint Elizabeth Healthcare, 20 Medical Village Dr, Suite 271, Edgewood, KY 41017 (E-mail: Mario.Castillo-Sang@stelizabeth.com).

J Thorac Cardiovasc Surg 2022;164:863-4

$0022-5223 / \$ 36.00$

Copyright (c) 2020 by The American Association for Thoracic Surgery

https://doi.org/10.1016/j.jtcvs.2020.10.056
}

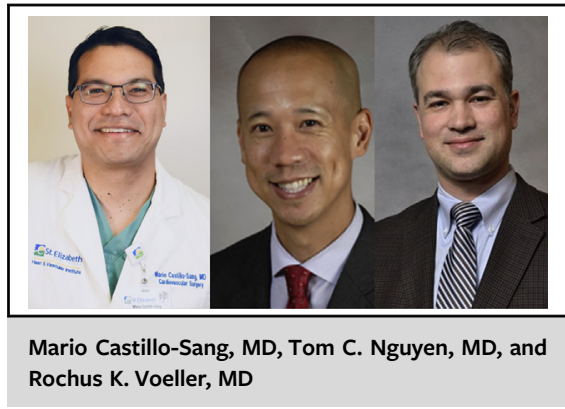

CENTRAL MESSAGE

The lost technique of papillary muscle approximation provides superior outcomes compared with restrictive annuloplasty in ischemic mitral valve repairs.

Animal studies have shown undersizing annuloplasty does not improve ventricular volumes or positively influence remodeling. ${ }^{8,9}$ Papillary muscle approximation (PMA), although not widely adopted, has favorable results in reducing regurgitation and improving ventricular volumes, ejection fraction, and ventricular remodeling at shortand long-term follow-up. ${ }^{10,11}$

$\mathrm{Xu}$ and colleagues ${ }^{12}$ present data from their ischemic mitral regurgitation swine model study comparing undersizing mitral annuloplasty (UMA) with PMA. Fifteen swine had an induced inferolateral infarction by occlusion of 